\title{
Introduction to the RIO Special Issue on Net Neutrality
}

\author{
Scott Wallsten ${ }^{1}$ (iD
}

Published online: 2 May 2017

(c) Springer Science+Business Media New York 2017

The U.S. Federal Communication Commission's (FCC's) "Open Internet Order" (which was promulgated in 2015) is arguably the latest salvo in a debate that has raged for at least a century on whether and how to regulate access to networks with very high fixed costs. The FCC's Order made two major changes to how the U.S. regulates broadband: First, it established broadband Internet service providers (ISPs) as "common carriers," which would allow the government to regulate the service more heavily. Second, it established one version of "network neutrality," which limits the ways in which ISPs can interact with and manage Internet traffic. For example, under the rules ISPs are not allowed to block sites or enter into paid prioritization agreements with particular sites.

Access rules are always and everywhere contentious, and the Open Internet Order is no exception. The authors in this special issue of the Review of Industrial Organization consider many aspects of the Order, including the longer history of competition policy in telecommunications, theoretical rationales for and against such regulation, its expected effects, the process by which the rules were considered, and what markets and experience tell us about its anticipated effects.

Scott Wallsten

swallsten@techpolicyinstitute.org

1 Technology Policy Institute, Washington, DC, USA 


\section{What Does “Competition” Mean?}

The FCC and many other agencies make promoting competition a key component of their agenda. The Open Internet Order was no exception. ${ }^{1}$ But there is no bright line between when an industry is "competitive" and when it is not. Amanda Delp and John Mayo review the history of regulatory thinking about the concept of competition. They discuss the development of the phrase "workable competition" in the mid-twentieth century and its evolution into "effective competition." They offer a definition of effective competition that they believe would be useful for policymaking today. Unfortunately, they conclude, the FCC has thus far not consistently applied any particular definition of competition.

\section{Net Neutrality in Theory}

Keith Hylton and Joseph Farrell both explore the theoretical arguments for and against rules that enforce some version of net neutrality. Hylton notes that net neutrality regulation is a transfer of wealth: If everyone pays the same amount, then varying demand across consumers means that some groups will subsidize other groups. In some cases similar wealth transfers can increase net welfare. Yet, he concludes, with information goods - including those affected by net neutrality rules — such subsidies tend to be regressive: benefiting high-income users at the expense of low-income users.

Net neutrality is, at its heart, about how the provider of an upstream good interacts with providers of downstream goods. Farrell explores these interactions and when vertical linkages promote competition and efficiency. He notes that a key determinant of whether the linkages promote or hinder competition in broadband markets depend on where the ISP "steers" the consumer. Even then, however, such steering can make the consumer better or worse off, depending on various conditions.

Michael Katz discusses the FCC's apparent disinterest in considering the economic logic for and against the net neutrality rules or in acknowledging the possibility of unintended consequences. He ultimately concludes "that the Commission has made several claims about the benefits of its policies that economics does not support." He further concludes that the Order is "likely to have several adverse and/or unintended consequences, including the stimulation of market trends that may undermine the regulations themselves."

\section{Net Neutrality in Practice}

It is too early to reach strong conclusions about the effects of the Open Internet Order, but past experience can provide some clues. A key question is how such rules are likely to affect investment.

\footnotetext{
${ }^{1}$ See, for example, paragraph 76 in Federal Communications Commission, "In the Matter of Protecting and Promoting the Open Internet," Report and Order on Remand, Declaratory Ruling, and Order, (February 6, 2015), https://apps.fcc.gov/edocs_public/attachmatch/FCC-15-24A1.pdf.
} 
Timothy Brennan, who was the FCC Chief Economist while the Open Internet Order was created and promulgated, notes that the record had little to offer that demonstrated a need for the rules. He reviews the four incidents in the previous ten years that might have fallen under the new rules. He points out that while the thin record suggests little reason for the rules, it also raises the question of why anyone cares. That is, if there have been almost no violations, then perhaps the rules are not binding in any case. His concern, however, is that the rules may bring closer the day that the FCC begins engaging in outright price regulation, which is likely to be harmful.

Thomas Hazlett and Joshua Wright evaluate the empirical claims that the FCC made in justifying the Order and determine that few hold up to scrutiny. They find that increases in "Title II"-like (common carrier) rules tended to reduce investment, while reductions in such rules tended to increase investment. They similarly anticipate that the Open Internet Order will cause providers to reduce investment.

Christopher Yoo points out that the Open Internet Order could effectively outlaw some common practices. In particular, so-called "zero rating" - in which data from certain sites do not count against data caps_could be banned. Yet, he argues, product and service differentiation is a key way that companies, especially new entrants, compete with each other. Rather than setting specific rules about zerorating, the FCC should, he contends, consider them on a case-by-case approach.

Michelle Connolly, Clement Lee, and Renhao Tan remind us that the rules may have unintended consequences. Most importantly, they may worsen the digital divide. In particular, the rules could lead to increased consumer prices, which would make broadband less affordable, and to reduced returns on investments, which would reduce the incentives for companies to invest in areas less likely to yield an economic return.

Robert Crandall steps back from the debate to ask what investors seem to think of the likely effects of the rules via an "event study" of stock market reactions to net neutrality news. He finds, surprisingly- that despite the heated rhetoric-the financial markets seem to have given a collective shrug. ISPs suffered no real downturn in their stock prices; and media companies, which many thought would be the beneficiaries of the rules, experienced no real increase.

\section{Conclusion}

Given the long history of the debate, anyone who thought the Open Internet Order would be the last word on this issue, at least in the United States, hasn't been paying attention. The issue is too contentious; supply and demand are changing too quickly; and regulatory agencies are too fickle to make credible commitments to reach a stable, well-accepted answer. Indeed, President Trump's first FCC Chairman, Ajit Pai, has made clear his desire to reverse both Title II and the net neutrality rules.

Perhaps the papers in this special issue will help the FCC Chairman and others think more fully about the range of issues that are inherently related to net neutrality. 